Braz J Med Biol Res, September 2012, Volume 45(9) 818-826

doi: 10.1590/S0100-879X2012007500116

Is arterial stiffness in HIV-infected individuals associated with HIV-related factors?

P. Monteiro, D.B. Miranda-Filho, F. Bandeira, H.R. Lacerda, H. Chaves, M.F.P.M. Albuquerque, U.R. Montarroyos and R.A.A. Ximenes

The Brazilian Journal of Medical and Biological Research is partially financed by

\section{Q}

da Ciência e Tecnologia

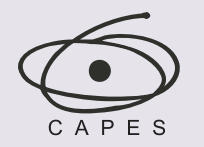

Ministério da Educação
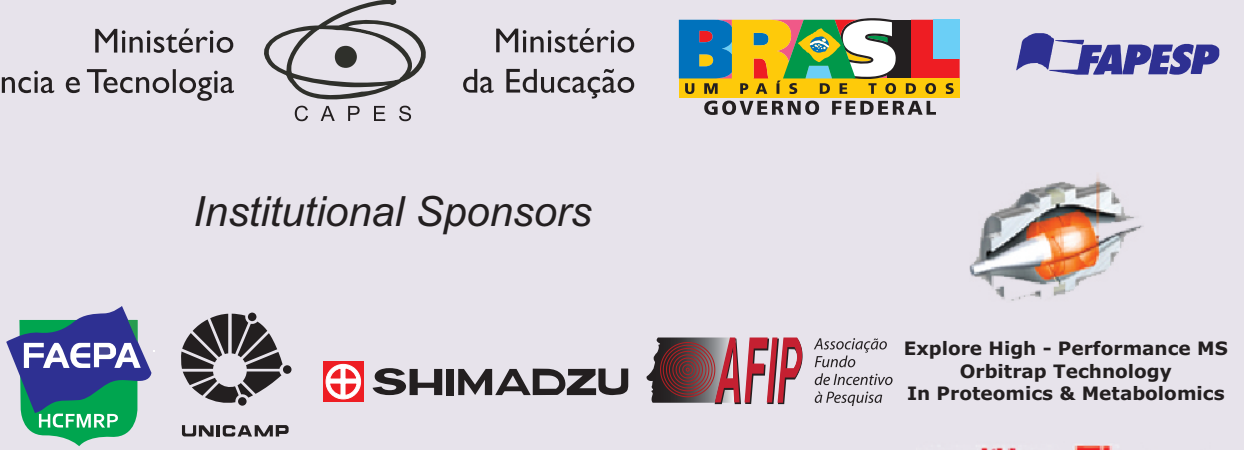

Institutional Sponsors

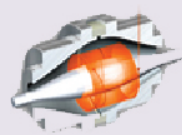

Ф SHIMADZU UNICAMP

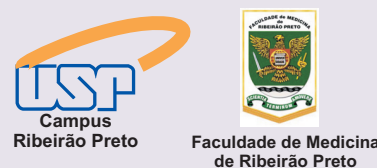
de Ribeirão Preto
de 


\title{
Is arterial stiffness in HIV-infected individuals associated with HIV-related factors?
}

\author{
P. Monteiro' ${ }^{1}$, D.B. Miranda-Filho², F. Bandeira ${ }^{3}$, H.R. Lacerda ${ }^{2,4}$, \\ H. Chaves ${ }^{5}$, M.F.P.M. Albuquerque ${ }^{6}$, U.R. Montarroyos $^{4}$ and R.A.A. Ximenes ${ }^{2,4}$ \\ ${ }^{1}$ Serviço de Doenças Infecciosas, Faculdade de Medicina, Universidade de Pernambuco, Recife, PE, Brasil \\ 2Departamento de Medicina Clínica, Faculdade de Medicina, \\ Universidade de Pernambuco, Recife, PE, Brasil \\ ${ }^{3}$ Serviço de Endocrinologia, Faculdade de Medicina, Universidade de Pernambuco, Recife, PE, Brasil \\ ${ }^{4}$ Departamento de Medicina Tropical, Faculdade de Medicina, \\ Universidade Federal de Pernambuco, Recife, PE, Brasil \\ ${ }^{5}$ Departamento de Cardiologia, Faculdade de Medicina, Universidade Federal de Pernambuco, \\ Recife, PE, Brasil \\ ${ }^{6}$ Centro de Pesquisa Aggeu Magalhães, FIOCRUZ, Recife, PE, Brasil
}

\begin{abstract}
We investigated the association between pulse wave velocity (PWV) and HIV infection, antiretroviral treatment-related characteristics, viral load, immune status, and metabolic changes in a cross-sectional study nested in a cohort of HIVIAIDS patients who have been followed for metabolic and cardiovascular changes since 2007. The study included patients recruited from the cohort $(\mathrm{N}=261)$ and a comparison group $(\mathrm{N}=82)$ of uninfected individuals, all enrolled from April to November 2009. Aortic stiffness was estimated using the carotid-femoral PWV (Complior-Artech, Paris, France). The groups were similar with respect to age, metabolic syndrome, diabetes mellitus, Framingham score, and use of antihypertensive and hypolipidemic medications. Hypertension was more frequent among the controls. Individuals with HIV had higher triglyceride, glucose and HDL cholesterol levels. Among individuals with HIVIAIDS, those with a nadir CD4 ${ }^{+}$T-cell count $<200 \mathrm{cells} / \mathrm{mm}^{3}$ had a higher $\mathrm{PWV}(\mathrm{P}=0.01)$. There was no statistically significant difference when subjects were stratified by gender. Heart rate, age, male gender, and blood pressure were independently correlated with PWV. Nadir CD4 ${ }^{+}$T-cell count did not remain in the final model. There was no significance difference in PWV between HIV-infected individuals and uninfected controls. PWV was correlated with age, gender, and blood pressure across the entire population and among those infected with HIV. We recommend cohort studies to further explore the association between inflammation related to HIV infection and/or immune reconstitution and antiretroviral use and PWV.
\end{abstract}

Key words: HIV; AIDS; Antiretroviral therapy; Arterial stiffness; Pulse wave velocity

\section{Introduction}

The typical course of HIV infection has changed since 1995, when the availability of antiretroviral therapy (ARV) resulted in a marked reduction in mortality rate (1). Since then, treatment-related toxicities have been identified, including an array of metabolic and body composition changes (2). Moreover the prevalence of well-established risk factors for cardiovascular disease (CVD) such as smoking, illicit drug use, dyslipidemia, and diabetes was found to be higher among HIV-infected individuals than age-matched controls. In addition, other possible factors contributing to CVD were recognized in this population such as lipodystrophy (LD), HIV-related immunodeficiency and immune activation $(3,4)$.

A number of studies have suggested that cumulative $A R V$ is associated with a higher risk of myocardial infarction (3,5-8). Alternatively, interruption of ARV was also found to be associated with increased cardiovascular risk when compared to continuous therapy (9). However, there is speculation about whether the risk assigned to this population is due to a higher prevalence of traditional cardiovascular factors or to their association with specific variables related to HIV infection itself.

Several methods have been used to assess subclinical atherosclerosis, such as tests to detect the functional capac-

Correspondence: P. Monteiro, Calle Galileo, 337, 2/3, Barcelona, España 08028. E-mail: polymonteiro@hotmail.com

Received December 22, 2011. Accepted June 28, 2012. Available online July 13, 2012. Published August 17, 2012. 
ity of the endothelium, the carotid intima-media thickness and coronary artery calcium score. While in some studies $(10,11)$ atherosclerosis was shown to be associated with HIV infection, the use of ARV, lymphocyte count, and inflammatory markers, others have emphasized the role of traditional risk factors (12). Carotid-femoral pulse wave velocity (PWV), a measure of the intrinsic stiffness of the aortic wall, is highly predictive of cardiovascular events (13-16). It has been shown to be predictive of cardiovascular morbidity and mortality in a large number of studies and therefore is considered to be the gold standard for the measurement of arterial stiffness (17).

To date, only a few studies have compared arterial stiffness in HIV-infected patients to that of uninfected individuals, especially in developing countries, and the data reported thus far do not permit a conclusive interpretation. The aim of the present study, carried out at two HIVIAIDS referral centers in Brazil, was to investigate the association between PWV and HIV infection and, in HIV-infected individuals, the association between PWV and ARV treatment-related characteristics, viral load, immune status, and metabolic changes.

\section{Material and Methods}

\section{Study population}

This was a cross-sectional study (nested in a cohort) conducted from April to November 2009. The study included male and female patients treated at HIVIAIDS outpatient clinics in Oswaldo Cruz and Correa Picanço Hospitals. Participants were recruited from a cohort that had been followed for metabolic and cardiovascular changes since 2007.

Individuals attending other specialty outpatient clinics at Oswaldo Cruz University Hospital, such as dermatology, odontology, ophthalmology, and general infectious disease, were asked to participate in the study as the control group. Patients were approached by interviewers during routine medical visits.

Inclusion criteria were being older than 18 years of age and having a negative test for HIV in the previous 6 months in the case of controls; patients with clinical signs of active infection or who had been hospitalized during the past three months were excluded. Pregnant women were also excluded. This study was approved by the Research Ethics Committee of Hospital Universitário Oswaldo Cruz (protocol No. 127/2006) and all subjects gave written informed consent to participate.

\section{Data collection}

After giving informed consent, the participants filled a standardized questionnaire and had their blood pressure, heart rate and anthropometric measurements taken under standard conditions. We recorded data on smoking, illicit drug use, history of CVD, hyperlipidemia, and use of antihypertensive and/or hypolipidemic agents.
Detailed information about ARV therapy, CD4 ${ }^{+} \mathrm{T}$-cell count, viral load, and a history of AIDS-defining illnesses were obtained from the medical records. Blood samples were collected after a 12-h fast and tested for CD4 ${ }^{+} \mathrm{T}$-cell count (flow cytometry, FacsCalibur three colors, Becton Dickinson, USA), viral load (enzymatic colorimetric method, Cobas Integra 400 II, Roche Diagnostics, Germany), total cholesterol, high-density cholesterol (HDL), triglycerides, and glucose (enzymatic method, Cobas Mira, Roche Diagnostics). Low-density cholesterol (LDL) was calculated indirectly using the Friedewald formula.

Metabolic syndrome was defined according to the Third Report of the National Cholesterol Education Program Expert Panel on Detection, Evaluation, and Treatment of High Blood Cholesterol in Adults (18). Hypertension was considered when the average of two measurements at different times of systolic blood pressure was equal to or greater than $140 \mathrm{mmHg}$ and/or diastolic blood pressure was $90 \mathrm{mmHg}$ or greater, or by self-reported treatment with medications. Diabetes mellitus was defined by fasting glucose $\geq 126 \mathrm{mg} /$ $\mathrm{dL}$ or current treatment. Subjects were classified according to body mass index based on measured weight and height, as normal $\left(\leq 25 \mathrm{~kg} / \mathrm{m}^{2}\right)$, overweight $\left(25-29.9 \mathrm{~kg} / \mathrm{m}^{2}\right)$, and obese $\left(\geq 30 \mathrm{~kg} / \mathrm{m}^{2}\right)$. The Framingham risk score, validated in the general population as a measure of coronary heart disease risk, was calculated (19).

To assess the patient's perception of changes in body fat distribution after starting ARV therapy, the participants answered a specific standardized questionnaire, which was constructed based on the findings of other studies $(20,21)$ that employed subjective criteria to define lipodystrophy (available from the author). Aortic stiffness was estimated by automatic and noninvasive measurement of carotid-femoral PWV according to the recommendations on procedures for the use of arterial stiffness in clinical practice (22).

The PWV measurements were performed by the same trained technician. The intraclass correlation coefficient, based on duplicate measurements taken from 20 participants, was 0.975. For the PWV measurement, we placed two transducers (TY-306, Fukuda Denshi Co., Japan) on the skin points of palpation of the right common carotid artery at the base of the neck and the right femoral artery at the groin, linked to an automatic processor from Complior (Artech, France). PWV was calculated as the distance between recording sites measured over the surface of the body, divided by the time interval between the feet of the pressure waves. The average of 10 different cardiac cycles at each site was used for analysis.

\section{Statistical analysis}

The analysis was performed in two stages. In the first stage, we compared the characteristics of HIV-infected individuals and controls and tested the association between HIV infection and PWV, with adjustment for the effect of other variables. 
In the second stage, we included only HIV-infected individuals and tested the association between the characteristics of this cohort and PWV. Continuous variables are reported as means \pm SD (or median and inter-quartile range, when appropriate) and categorical variables are reported as percentage. To test the statistical significance of differences between means, the continuous variables displaying normal distribution and homogeneity of variance were analyzed using parametric tests, i.e., the Student $t$-test and analysis of variance (ANOVA). The non-parametric Mann-Whitney and Kruskal-Wallis tests were for variables that did not have a normal distribution. The chi-square test was used to compare categorical variables. Variables that did not show a normal distribution were log-transformed to calculate the correlation coefficient. For PWV, the most appropriate transformation was inverse PWV.

We used linear regression models to test the association between PWV and all independent variables and Pearson correlation coefficients to assess the correlation between nadir CD4 ${ }^{+}$T-cell count and PWV.

Finally, all variables that showed a statistically significant association with PWV were included in the multiple regression model. We used a forward regression method for inclusion of variables in the model. Variables that exhibited a $\mathrm{P}$ value of less than 0.05 in their correlation with PWV remained in the final model. Statistical significance was defined as $P<0.05$. Data analysis was performed using the STATA 10.0 software (USA).

\section{Results}

\section{Characteristics of the study population}

Arterial stiffness was determined in 343 individuals, $261 \mathrm{HIV}$-infected and 82 uninfected controls. The two groups were similar with respect to age, prevalence of metabolic syndrome, diabetes mellitus, and risk of coronary artery disease (CAD) (as assessed by the Framingham score) and the use of antihypertensive and hypolipidemic medications. The age of the participants ranged from 20 to 70 years, with a median of 43 years for the entire study population.

Forty-nine percent of HIV-infected individuals had hypertriglyceridemia, in contrast to $25 \%$ of the controls. Twenty-two percent of HIV-infected individuals had an elevated blood glucose level and/or diabetes compared to only $10 \%$ of controls. Low serum levels of HDL cholesterol were found in $62 \%$ of individuals with HIV and in $43 \%$ of controls. The clinical and laboratory characteristics of the participants are shown in Table 1. test).

\section{Comparison of PWV values according to the characteristics of the entire study population}

There was no statistically significant difference in mean PWV values between HIV-infected and uninfected individuals. In both groups, PWV was significantly higher in individuals aged 40 years or older, in males and in patients with metabolic syndrome, hypertension and diabetes mellitus. Similarly, PWV was associated with a risk of CAD within 10 years according to the Framingham equation. We did not observe an association between PWV and smoking, level of physical activity, body mass index or weight. The results of the multiple linear regression analysis are reported in Table 2.

\section{Comparison of PWV values according to the characteristics of HIV-infected individuals}

At the time of this study, 233 (89\%) HIV-infected individuals had been using ARV therapy for 5.5 years on average. The most widely used ARV regimen consisted of two nucleoside analogue reverse transcriptase inhibitors (NRTIs) and

Table 1. Clinical and laboratory characteristics of the study population.

\begin{tabular}{|c|c|c|}
\hline & $\begin{array}{l}\text { HIV-infected patients } \\
\qquad(\mathrm{N}=261)\end{array}$ & $\begin{array}{l}\text { Control subjects } \\
\qquad(\mathrm{N}=82)\end{array}$ \\
\hline Age (years) & $42 \pm 8$ & $42 \pm 11$ \\
\hline Males & $57.8 \%(151)$ & $32.9 \%(27)$ \\
\hline \multicolumn{3}{|l|}{ Ethnic group } \\
\hline White & $28 \%(73)$ & $24 \%(19)$ \\
\hline Asian & $69 \%(180)$ & $74 \%(59)$ \\
\hline Black/Mixed & $0.7 \%(2)$ & $2.5 \%(2)$ \\
\hline Indigenous & $2 \%(6)$ & $0 \%$ \\
\hline Systolic blood pressure $(\mathrm{mmHg})$ & $122 \pm 11(261)$ & $124 \pm 13(82)$ \\
\hline Diastolic blood pressure $(\mathrm{mmHg})$ & $77 \pm 8^{*}(261)$ & $80 \pm 10(82)$ \\
\hline Heart rate $(\mathrm{bpm})$ & $75 \pm 11(261)$ & $72 \pm 10(82)$ \\
\hline Total cholesterol (mg/dL) & $189 \pm 49(258)$ & $184 \pm 43(65)$ \\
\hline Low-density lipoprotein (mg/dL) & $109 \pm 42(256)$ & $107 \pm 38(61)$ \\
\hline High-density lipoprotein (mg/dL) & $40^{*}(35-48)(256)$ & $48(39-62)(74)$ \\
\hline Triglycerides (mg/dL) & $145^{*}(99-216)(259)$ & $105(83-149)(73)$ \\
\hline Glucose (mg/dL) & $89^{*}(82-98)(257)$ & $81(74-89)(77)$ \\
\hline Metabolic syndrome & $28 \%(258)$ & $23 \%(79)$ \\
\hline Hypertension & $20 \%{ }^{*}(261)$ & $32 \%(82)$ \\
\hline Diabetes & $2 \%(255)$ & $1 \%(77)$ \\
\hline Smoking & $23 \% *(261)$ & $6 \%(81)$ \\
\hline Illicit drug use & $20 \% *(261)$ & $2 \%(81)$ \\
\hline Body mass index $\left(\mathrm{kg} / \mathrm{m}^{2}\right)$ & $24 \pm 4^{*}(260)$ & $27 \pm 4(82)$ \\
\hline Use of antihypertensives & $5 \%(261)$ & $6 \%(82)$ \\
\hline Use of hypolipidemics & $3 \%(261)$ & $6 \%(82)$ \\
\hline Framingham score $<10 \%$ & $85 \%(209)$ & $84 \%(59)$ \\
\hline Pulse wave velocity $(\mathrm{m} / \mathrm{s})$ & $7.85 \pm 1.50(261)$ & $7.75 \pm 1.54(82)$ \\
\hline
\end{tabular}

Data are reported as means \pm SD or median and inter-quartile range. ${ }^{*} P<0.05$ compared to control group (Student $t$-test, Mann-Whitney test and chi-square 
Table 2. Clinical and laboratory determinants of pulse wave velocity $(\mathrm{m} / \mathrm{s})$ of 343 participants.

\begin{tabular}{|c|c|c|c|c|}
\hline & \multicolumn{2}{|c|}{ Univariate model } & \multicolumn{2}{|c|}{$\begin{array}{c}\text { Multivariate model } \\
\text { (adjusted for clinical } \\
\text { and HIV-related covariates) }\end{array}$} \\
\hline & $\beta$ & $\mathrm{P}$ & $\beta$ & $P$ \\
\hline \multicolumn{5}{|l|}{ Clinical } \\
\hline HIV-infected & -0.0021 & 0.483 & -0.0013 & 0.575 \\
\hline Age (years) & -0.0013 & 0.000 & -0.0011 & 0.000 \\
\hline Males & -0.0104 & 0.000 & -0.0096 & 0.000 \\
\hline Ethnic group: White (\%) & 0.0015 & 0.705 & - & \\
\hline Smoking (\%) & -0.0030 & 0.248 & - & \\
\hline Illicit drug use (\%) & 0.0045 & 0.203 & - & \\
\hline Antihypertensive medication use (\%) & 0.00003 & 0.997 & - & \\
\hline Systolic blood pressure (mmHg) & -0.0965 & 0.000 & -0.0308 & 0.029 \\
\hline Diastolic blood pressure $(\mathrm{mmHg})$ & -0.0857 & 0.000 & -0.0447 & 0.000 \\
\hline Body mass index $\left(\mathrm{kg} / \mathrm{m}^{2}\right)$ & -0.0053 & 0.491 & - & \\
\hline Heart rate (bpm) & -0.0262 & 0.003 & -0.0190 & 0.005 \\
\hline \multicolumn{5}{|l|}{ Laboratory } \\
\hline Low-density lipoprotein $<160$ (mg/dL) & 0.0058 & 0.183 & - & - \\
\hline Total cholesterol >200 (mg/dL) & -0.0030 & 0.271 & - & - \\
\hline Triglycerides (mg/dL) & -0.0088 & 0.001 & - & - \\
\hline Glycemia >100 (mg/dL) & -0.0090 & 0.006 & - & - \\
\hline
\end{tabular}

Linear regression models were used for statistical analysis.

one non-nucleoside analogue reverse transcriptase inhibitor (NNRTI; 48\%), followed by a combination of two NRTIs and a protease inhibitor (PI) with ritonavir (33\%). Only $12 \%$ were using regimens containing protease inhibitors without ritonavir, and $7 \%$ used some combination of drugs other than those three. The average time from diagnosis of HIV infection to the time of the study was eight years. Seventy-six percent had an undetectable serum viral load ( $<50$ copies $/ \mathrm{mL}$ ). The mean $\mathrm{CD}^{+}{ }^{+} \mathrm{T}$-cell count was 533 cells $/ \mathrm{mm}^{3}$ and $89 \%$ had a CD4 ${ }^{+} \mathrm{T}$-cell count equal to or greater than 200 cells $/ \mathrm{mm}^{3}$. Among individuals with HIV/ AIDS, neither the recent CD4 ${ }^{+}$T-cell count nor viral load at the time of the study showed any statistically significant association with PWV.

On the other hand, individuals with a nadir CD4 ${ }^{+}$T-cell count $<200$ cells $/ \mathrm{mm}^{3}$ had a statistically significant $(P=$ $0.01)$ higher PWV $(8.01 \pm 1.53)$ than those with a nadir $\mathrm{CD}^{+}$T-cell count $\geq 200$ cells $/ \mathrm{mm}^{3}(7.62 \pm 1.40)$. When subjects were stratified by gender the difference was not statistically significant (men, nadir CD4 ${ }^{+}$T-cell count $<200$ cells $/ \mathrm{mm}^{3}$ : PWV $8.24 \pm 1.5$ and CD4 ${ }^{+}$T-cell count $\geq 200$ cells $/ \mathrm{mm}^{3}$ : PWV $8.01 \pm 1.63$; women, nadir CD4 ${ }^{+}$T-cell count $<200$ cells $/ \mathrm{mm}^{3}$ : PWV $7.5 \pm 1.5$ and $\mathrm{CD}^{+}{ }^{+}$T-cell count $\geq 200$ cells $/ \mathrm{mm}^{3}$ : PWV $\left.7.33 \pm 1.13\right)$. Comparisons of mean PWV values with specific HIV characteristics are shown in Table 3.

The use of ARV, NRTI, NNRTI, and the length of PI were the only variables for which ARV treatment was correlated with higher PWV measurements. Information regarding antiretroviral treatment is outlined in Table 4. These factors were no longer statistically significant after adjusting for age in the multivariate analysis model. In the multiple regression model (Table 5), heart rate, age, male gender, and systolic and diastolic blood pressures were independently correlated with PWV.

\section{Discussion}

This study compared treated and untreated HIV-infected individuals to uninfected controls and found similar carotidfemoral PWV measures for the two groups. Individuals with HIV had a high frequency of elevated levels of serum triglycerides and low levels of serum HDL cholesterol. The frequency of hypertension was higher in the uninfected controls (32 vs 20\%, P = 0.02) and the frequency in HIVinfected patients was similar to previously reported values (23). Since the carotid-femoral segment of the vasculature is highly sensitive to age-related changes and increases in blood pressure (24), the higher prevalence of hypertension in the control group could explain, at least in part, the absence of association of PWV and HIV status. Even after adjusting for systolic or diastolic blood pressure in the multivariate analysis, the results remained unchanged.

Systolic and diastolic blood pressure, age, male gender, and heart rate were significant predictors of PWV, findings highly consistent with those of studies conducted on unin- 
Table 3. Pulse wave velocity (PWV) values in relation to characteristics associated with HIV infection and its treatment.

\begin{tabular}{|c|c|c|c|}
\hline Variable & $\mathrm{PWV}(\mathrm{m} / \mathrm{s})$ & $P$ & HIV-infected patients, $\mathrm{N}(\%)$ \\
\hline \multicolumn{4}{|c|}{ Recent CD4 ${ }^{+}$T-cell count } \\
\hline$<200$ cells $/ \mathrm{mm}^{3}$ & $7.75 \pm 1.51$ & 0.75 & $26(10 \%)$ \\
\hline$\geq 200$ cells $/ \mathrm{mm}^{3}$ & $7.85 \pm 1.50$ & & $233(90 \%)$ \\
\hline \multicolumn{4}{|c|}{ Nadir CD4 ${ }^{+}$T-cell count } \\
\hline$<200$ cells $/ \mathrm{mm}^{3}$ & $8.01 \pm 1.53$ & 0.01 & $150(57 \%)$ \\
\hline$\geq 200$ cells $/ \mathrm{mm}^{3}$ & $7.62 \pm 1.40$ & & $110(43 \%)$ \\
\hline \multicolumn{4}{|c|}{ Recent viral load, $\log _{10}$ copies $/ \mathrm{mL}$} \\
\hline$<4.0$ & $7.84 \pm 1.50$ & 0.94 & $224(88 \%)$ \\
\hline $4.0-5.0$ & $7.97 \pm 1.64$ & & $23(9 \%)$ \\
\hline$>5.0$ & $7.78 \pm 0.78$ & & $8(3 \%)$ \\
\hline \multicolumn{4}{|c|}{ Maximum viral load, $\log _{10}$ copies $/ \mathrm{mL}$} \\
\hline$<4.0$ & $7.87 \pm 1.57$ & 0.11 & $59(23 \%)$ \\
\hline $4.0-5.0$ & $7.66 \pm 1.49$ & & $87(33 \%)$ \\
\hline$>5.0$ & $7.98 \pm 1.45$ & & $114(44 \%)$ \\
\hline \multicolumn{4}{|c|}{ Length of HIV infection } \\
\hline$<5$ years & $7.75 \pm 1.50$ & 0.30 & $81(31 \%)$ \\
\hline$\geq 5$ years & $7.89 \pm 1.48$ & & $180(69 \%)$ \\
\hline \multicolumn{4}{|l|}{ Lipodystrophy } \\
\hline Yes & $7.96 \pm 1.42$ & 0.38 & $123(53 \%)$ \\
\hline No & $7.86 \pm 1.59$ & & $110(47 \%)$ \\
\hline \multicolumn{4}{|l|}{ Metabolic syndrome } \\
\hline Yes & $8.07 \pm 1.38$ & 0.04 & $78(30 \%)$ \\
\hline No & $7.76 \pm 1.52$ & & $180(70 \%)$ \\
\hline
\end{tabular}

Data are reported as means \pm SD. Student $t$-test, one-way ANOVA, Mann-Whitney test, and Kruskal-Wallis test were used for statistical analysis.

fected patients. The independent association between PWV and heart rate has been reported (25). Heart rate may be a confounding factor that should be incorporated into any analysis related to PWV (26).

Despite the small number of diabetics, we failed to detect consistent associations between diabetes mellitus and PWV. The same applies to smoking, total cholesterol and fractions and triglycerides. According to a recent systematic review, age and blood pressure were significantly and independently associated with PWV in 91 and $90 \%$ of studies, respectively (26). In the same study, the presence of diabetes mellitus was associated with PWV in $52 \%$ of studies and smoking in $14 \%$. Five percent of studies found a significant association with total cholesterol and LDL cholesterol, and HDL was significantly associated in $11 \%$ of studies. Only $3 \%$ reported a significant association with triglyceride levels.

Preliminary studies that assessed arterial stiffness in the HIV population detected increased arterial stiffness in HIV-infected individuals compared to uninfected controls $(27,28)$. Considering HIV treatment and the role of ARV drugs in the development of arterial stiffness, the use of ARV $(29,30)$ and its duration $(27,29,31,32)$ as well as the use of PI $(31,32)$ have been associated with arterial stiffness. However, the majority of these studies were characterized by their relatively small sample size, ranging from 32 to 56 individuals, compromising their ability to determine the role of HIV-related variables in arterial stiffness. Furthermore, the interpretation of prior studies is not easy on account of differences in the profile of participants and in the methods used to assess arterial stiffness as well as due to the presence of confounding variables including traditional cardiovascular risk factors, use of distinct ARV combinations, and duration of HIV infection.

Furthermore, in 2009 van Vonderen et al. (33) observed increased stiffness in the femoral artery 24 months after the initiation of ARV, with no changes in systemic arterial stiffness assessed by aortic augmentation index. Indeed, the femoral segment of the vasculature, which consists mostly of smooth muscle cells, is characterized by greater rigidity and sensitivity to vasoactive substances, especially those of endothelial origin (24). The muscular femoral artery is also more susceptible to the effects of fat accumulation, as well as glucose intolerance and metabolic syndrome (34). In contrast, there was a reduction in the levels of endothelial adhesion molecules (ICAM-1 and VCAM-1) and levels of 
von Willebrand factor (33).

In another study by the same investigators, 77 HIV-infected men [ 55 on highly active ARV therapy (HAART) and 22 treatment-naive individuals] were found to have similar PWV compared to uninfected controls (29).

A recent study compared measures of arterial stiffness using radial artery tonometry in 276 HIV-infected and 67 HIV-uninfected Rwandan women. They reported that HIV infection was not associated with greater arterial wave reflection in women with little exposure to ARV therapy and without other CVD risk factors (35). Thus, the lack of association between arterial stiffness and HIV status in our study is not surprising.

Among those infected with HIV, $89 \%$ were taking ARV therapy. The frequency of NNRTI use $(66 \%)$ was similar to the PI use $(57 \%)$. The average time from the diagnosis of HIV infection to being enrolled in the study was 8 years. ARV therapy-related characteristics did not appear to be associated with arterial stiffness in adjusted analyses.

LD was present in $53 \%$ of individuals using ARV therapy, in agreement with previous studies $(36,37)$. We did not observe an association between LD and arterial stiffness, as also reported by others $(29,31)$.

In addition, $76 \%$ of the individuals had an undetectable viral load ( $<50$ copies $/ \mathrm{mL}$ ), and $89 \%$ had a recent $\mathrm{CD}^{+}{ }^{+} \mathrm{T}$-cell count equal to or greater than 200 cells $/ \mathrm{mm}^{3}$. These data, besides reflecting the prevalent use of ARV drugs, may also suggest that the inflammatory effects of HIV on the vasculature were attenuated and, therefore, altered the pathogenic process, which contributes to CVD by means unrelated to the metabolic pathway. Endothelial activation and dysfunction have been proposed as plausible links between HIV infection and atherosclerosis $(38,39)$.

Among HIV-infected patients, a recent CD4 ${ }^{+}$ T-cell count was not significantly correlated with PWV. There were also no significant differences in PWV between subjects with CD4 count $<200$ and those with CD4 counts $\geq 200$ cells $/ \mathrm{mm}^{3}$, as well as with the threshold of 350 cells/ $\mathrm{mm}^{3}$.

Finally, the nadir CD4 ${ }^{+}$T-cell count $<200$ cells $/ \mathrm{mm}^{3}$ was associated with PWV, but after adjustment for clinical and HIV-related covariates it was no longer associated. Previous studies have shown conflicting results, with some reports of an association between a lower nadir CD4 ${ }^{+} \mathrm{T}$ cell count and arterial stiffness $(32,40)$ and other reports of no association (31). The results of a more recent trial showed that the nadir CD4 ${ }^{+}$T-cell count, as represented by a nadir CD4 ${ }^{+} \mathrm{T}$-cell count below 350 cells $/ \mathrm{mm}^{3}$, is a
Table 4. Pulse wave velocity (PWV) values in relation to characteristics associated with antiretroviral therapy.

\begin{tabular}{|c|c|c|c|}
\hline & $\mathrm{PWV}(\mathrm{m} / \mathrm{s})$ & $P$ & HIV-infected patients \\
\hline \multicolumn{4}{|l|}{ ARV use } \\
\hline Yes & $7.92 \pm 1.50$ & 0.03 & $233(89 \%)$ \\
\hline No & $7.26 \pm 1.25$ & & $28(11 \%)$ \\
\hline \multicolumn{4}{|l|}{ PI use } \\
\hline Yes & $7.96 \pm 1.56$ & 0.17 & $150(57 \%)$ \\
\hline No & $7.68 \pm 1.36$ & & $111(43 \%)$ \\
\hline \multicolumn{4}{|l|}{ NRTI use } \\
\hline Yes & $7.92 \pm 1.50$ & 0.04 & $229(88 \%)$ \\
\hline No & $7.34 \pm 1.25$ & & $32(12 \%)$ \\
\hline \multicolumn{4}{|l|}{ NNRTI use } \\
\hline Yes & $8.01 \pm 1.53$ & 0.01 & $173(66 \%)$ \\
\hline No & $7.51 \pm 1.34$ & & $88(34 \%)$ \\
\hline \multicolumn{4}{|l|}{ Time on ARV } \\
\hline$<2$ years & $7.70 \pm 1.50$ & 0.27 & $55(24 \%)$ \\
\hline 2-4 years & $7.76 \pm 1.30$ & & $44(19 \%)$ \\
\hline$>4$ years & $8.05 \pm 1.55$ & & $134(58 \%)$ \\
\hline \multicolumn{4}{|c|}{ PI cumulative duration } \\
\hline$<2$ years & $7.67 \pm 1.51$ & 0.02 & $54(36 \%)$ \\
\hline $2-4$ years & $7.68 \pm 1.49$ & & $38(25 \%)$ \\
\hline$>4$ years & $8.41 \pm 1.58$ & & $58(39 \%)$ \\
\hline \multicolumn{4}{|c|}{ NRTI cumulative duration } \\
\hline$<2$ years & $7.72 \pm 1.52$ & 0.21 & $54(24 \%)$ \\
\hline $2-4$ years & $7.69 \pm 1.27$ & & $44(19 \%)$ \\
\hline$>4$ years & $8.07 \pm 1.57$ & & $131(57 \%)$ \\
\hline \multicolumn{4}{|c|}{ NNRTI cumulative duration } \\
\hline$<2$ years & $7.90 \pm 1.56$ & 0.48 & $61(35 \%)$ \\
\hline $2-4$ years & $8.33 \pm 1.80$ & & $30(17 \%)$ \\
\hline$>4$ years & $7.97 \pm 1.40$ & & $82(48 \%)$ \\
\hline
\end{tabular}

Data are reported as means \pm SD or number with percent in parentheses. $\mathrm{ARV}=$ antiretroviral therapy; $\mathrm{PI}=$ protease inhibitor; $\mathrm{NRTI}=$ nucleoside analogue reverse transcriptase inhibitor; NNRTI = non-nucleoside analogue reverse transcriptase inhibitor. Student $t$-test, one-way ANOVA, Mann-Whitney test, and Kruskal-Wallis test were used for statistical analysis.

predictor of PWV (40). The association appeared to be independent of other factors known to influence measures of arterial stiffness such as age, blood pressure, diabetes mellitus, hypercholesterolemia, and HAART duration (40). Our study differs from the latter study because our sample included both genders and we used a different threshold for nadir CD4 ${ }^{+}$T-cell count. However, when the analysis was stratified by gender there was no association between nadir CD4 ${ }^{+}$T-cell count and PWV either for men $(N=151)$ or for women $(N=110)$, even in univariate analysis.

Our study has limitations common to a cross-sectional observational study and, as such, it is subject to potential selection biases and limitations in establishing causality. On the other hand, this is one of the largest sample sizes investigated in studies published on this issue. The novel 
Table 5. Clinical, laboratory, HIV- and ARV-related determinants of pulse wave velocity $(\mathrm{m} / \mathrm{s})$ of $261 \mathrm{HIV}$-infected individuals.

\begin{tabular}{|c|c|c|c|c|}
\hline & \multicolumn{2}{|c|}{ Univariate model } & \multicolumn{2}{|c|}{$\begin{array}{l}\text { Multivariate model (adjusted for } \\
\text { clinical and HIV-related covariates) }\end{array}$} \\
\hline & $\beta$ & $\mathrm{P}$ & $\beta$ & $\mathrm{P}$ \\
\hline \multicolumn{5}{|l|}{ Clinical } \\
\hline Age & -0.0012 & 0.000 & -0.0010 & 0.000 \\
\hline Men & -0.0125 & 0.000 & -0.0094 & 0.000 \\
\hline Ethnic group: White (\%) & -0.0002 & 0.963 & - & \\
\hline Smoking (\%) & -0.0024 & 0.398 & - & \\
\hline Illicit drug use (\%) & 0.0047 & 0.191 & - & \\
\hline Antihypertensive medication use (\%) & -0.0007 & 0.913 & - & \\
\hline Systolic blood pressure $(\mathrm{mmHg})$ & -0.0925 & 0.000 & -0.0324 & 0.051 \\
\hline Diastolic blood pressure $(\mathrm{mmHg})$ & -0.0081 & 0.000 & -0.0438 & 0.003 \\
\hline Body mass index $\left(\mathrm{kg} / \mathrm{m}^{2}\right)$ & 0.0020 & 0.819 & - & \\
\hline Heart rate $(\mathrm{bpm})$ & -0.0275 & 0.005 & -0.0147 & 0.065 \\
\hline \multicolumn{5}{|l|}{ Laboratory } \\
\hline Low-density lipoprotein <160 (mg/dL) & 0.0040 & 0.407 & - & - \\
\hline Total cholesterol >200 (mg/dL) & 0.0003 & 0.905 & - & - \\
\hline Triglycerides (mg/dL) & -0.00002 & 0.016 & - & - \\
\hline Glycemia >100 (mg/dL) & 0.0061 & 0.081 & - & - \\
\hline \multicolumn{5}{|l|}{ HIV-related } \\
\hline Length of HIV infection $\geq 5$ years & -0.0029 & 0.358 & - & - \\
\hline ARV use & -0.0105 & 0.024 & - & - \\
\hline Time on $A R V>5$ years & -0.0126 & 0.010 & - & - \\
\hline Nadir CD4 ${ }^{+}$T-cell count $<200$ cells $/ \mathrm{mm}^{3}$ & -0.0058 & 0.047 & - & - \\
\hline Recent CD4 ${ }^{+}$T-cell count $<200$ cells $/ \mathrm{mm}^{3}$ & 0.0016 & 0.730 & - & - \\
\hline Current detected viral load $\left(\log _{10}\right.$ cells $\left./ \mathrm{mm}^{3}\right)$ & -0.0026 & 0.416 & - & - \\
\hline Maximum viral load (>5.0 $\log _{10}$ copies $/ \mathrm{mL}$ ) & -0.0043 & 0.143 & - & - \\
\hline \multicolumn{5}{|l|}{ ARV-related } \\
\hline PI use & -0.0038 & 0.190 & - & - \\
\hline NNRTI use & -0.0082 & 0.007 & - & - \\
\hline D4T use & -0.0057 & 0.103 & - & - \\
\hline TDF use & -0.0031 & 0.358 & - & - \\
\hline EFV use & 0.0010 & 0.719 & - & - \\
\hline$A B C$ use & 0.0184 & 0.080 & - & - \\
\hline
\end{tabular}

$\mathrm{ARV}=$ antiretroviral therapy; $\mathrm{PI}=$ protease inhibitor; NNRTI = non-nucleoside analogue reverse transcriptase inhibitor; $\mathrm{D} 4 \mathrm{~T}$ = stavudine; TDF = tenofovir; EFZ = efavirenz; $\mathrm{ABC}=$ abacavir. Linear regression models were used for statistical analysis.

aspect of the present study is that it included treated and untreated HIV-infected patients of both genders and especially outpatient clinic subjects as controls. The sample size is also the strength of the study, which is the largest study examining arterial stiffness to date. The participants were recruited from a longitudinal cohort, and thus may provide important initial evidence addressing the impact of HIV on cardiovascular risk in ongoing follow-up studies.

The present results indicate that HIV infection was not associated with increased PWV. On the other hand, age, gender and blood pressure were strongly associated with PWV. The contribution of other cardiovascular risk factors was found to be nonsignificant. Our findings do not provide evidence of an association between HIV-related characteristics and PWV. However, due to common limitations in cross-sectional studies, we would recommend additional cohort studies to further explore the association between inflammation related to HIV infection and/or immune reconstitution and ARV use and PWV.

\section{Acknowledgments}

Research supported by Ministério da Saúde do Brasil (\#185/7 SA-4917/2007). 


\section{References}

1. Bhaskaran $\mathrm{K}$, Hamouda $\mathrm{O}$, Sannes M, Boufassa F, Johnson AM, Lambert PC, et al. Changes in the risk of death after HIV seroconversion compared with mortality in the general population. JAMA 2008; 300: 51-59.

2. Grinspoon S, Carr A. Cardiovascular risk and body-fat abnormalities in HIV-infected adults. N Engl J Med 2005; 352: 48-62.

3. Currier JS, Lundgren JD, Carr A, Klein D, Sabin CA, Sax PE, et al. Epidemiological evidence for cardiovascular disease in HIV-infected patients and relationship to highly active antiretroviral therapy. Circulation 2008; 118: e29-e35.

4. Martinez E, Larrousse M, Gatell JM. Cardiovascular disease and HIV infection: host, virus, or drugs? Curr Opin Infect Dis 2009; 22: 28-34.

5. Currier JS, Taylor A, Boyd F, Dezii CM, Kawabata H, Burtcel $\mathrm{B}$, et al. Coronary heart disease in HIV-infected individuals. J Acquir Immune Defic Syndr 2003; 33: 506-512.

6. Holmberg SD, Moorman AC, Williamson JM, Tong TC, Ward DJ, Wood KC, et al. Protease inhibitors and cardiovascular outcomes in patients with HIV-1. Lancet 2002; 360: 17471748.

7. Friis-Moller N, Sabin CA, Weber R, d'Arminio MA, El-Sadr WM, Reiss $P$, et al. Combination antiretroviral therapy and the risk of myocardial infarction. N Engl J Med 2003; 349: 1993-2003.

8. Mary-Krause M, Cotte L, Simon A, Partisani M, Costagliola D. Increased risk of myocardial infarction with duration of protease inhibitor therapy in HIV-infected men. AIDS 2003; 17: 2479-2486.

9. El-Sadr WM, Lundgren JD, Neaton JD, Gordin F, Abrams D, Arduino RC, et al. CD4+ count-guided interruption of antiretroviral treatment. N Engl J Med 2006; 355: 2283-2296.

10. Giuliano IC, de Freitas SF, de Souza M, Caramelli B. Subclinic atherosclerosis and cardiovascular risk factors in HIVinfected children: PERI study. Coron Artery Dis 2008; 19: 167-172.

11. Ross AC, Rizk N, O'Riordan MA, Dogra V, El-Bejjani D, Storer N, et al. Relationship between inflammatory markers, endothelial activation markers, and carotid intima-media thickness in HIV-infected patients receiving antiretroviral therapy. Clin Infect Dis 2009; 49: 1119-1127.

12. Mangili A, Gerrior J, Tang AM, O'Leary DH, Polak JK, Schaefer EJ, et al. Risk of cardiovascular disease in a cohort of HIV-infected adults: a study using carotid intima-media thickness and coronary artery calcium score. Clin Infect Dis 2006; 43: 1482-1489.

13. London GM, Marchais SJ, Guerin AP, Pannier B. Arterial stiffness: pathophysiology and clinical impact. Clin Exp Hypertens 2004; 26: 689-699.

14. Laurent S, Boutouyrie P, Asmar R, Gautier I, Laloux B, Guize $\mathrm{L}$, et al. Aortic stiffness is an independent predictor of allcause and cardiovascular mortality in hypertensive patients. Hypertension 2001; 37: 1236-1241.

15. Mattace-Raso FU, van der Cammen TJ, Hofman A, van Popele NM, Bos ML, Schalekamp MA, et al. Arterial stiffness and risk of coronary heart disease and stroke: the Rotterdam Study. Circulation 2006; 113: 657-663.

16. Willum-Hansen T, Staessen JA, Torp-Pedersen C, Rasmussen $\mathrm{S}$, Thijs $\mathrm{L}$, Ibsen $\mathrm{H}$, et al. Prognostic value of aortic pulse wave velocity as index of arterial stiffness in the general population. Circulation 2006; 113: 664-670.

17. Laurent S, Cockcroft J, Van Bortel L, Boutouyrie P, Giannattasio C, Hayoz D, et al. Expert consensus document on arterial stiffness: methodological issues and clinical applications. Eur Heart J 2006; 27: 2588-2605.

18. Third Report of the National Cholesterol Education Program (NCEP) Expert Panel on Detection, Evaluation, and Treatment of High Blood Cholesterol in Adults (Adult Treatment Panel III) final report. Circulation 2002; 106: 3143-3421.

19. Wilson PW, D'Agostino RB, Levy D, Belanger AM, Silbershatz $\mathrm{H}$, Kannel WB. Prediction of coronary heart disease using risk factor categories. Circulation 1998; 97: 18371847.

20. Lichtenstein KA, Ward DJ, Moorman AC, Delaney KM, Young B, Palella FJ Jr, et al. Clinical assessment of HIVassociated lipodystrophy in an ambulatory population. AIDS 2001; 15: 1389-1398.

21. Carr A, Emery S, Law M, Puls R, Lundgren JD, Powderly WG. An objective case definition of lipodystrophy in HIVinfected adults: a case-control study. Lancet 2003; 361: 726-735.

22. Van Bortel LM, Duprez D, Starmans-Kool MJ, Safar ME, Giannattasio C, Cockcroft J, et al. Clinical applications of arterial stiffness, Task Force III: recommendations for user procedures. Am J Hypertens 2002; 15: 445-452.

23. Arruda Junior ER, Lacerda HR, Moura LC, Albuquerque MF, Miranda Filho DB, Diniz GT, et al. Risk factors related to hypertension among patients in a cohort living with HIV/ AIDS. Braz J Infect Dis 2010; 14: 281-287.

24. Safar ME, Levy BI, Struijker-Boudier H. Current perspectives on arterial stiffness and pulse pressure in hypertension and cardiovascular diseases. Circulation 2003; 107: 28642869.

25. Sa Cunha R, Pannier B, Benetos A, Siche JP, London GM, Mallion JM, et al. Association between high heart rate and high arterial rigidity in normotensive and hypertensive subjects. J Hypertens 1997; 15: 1423-1430.

26. Cecelja M, Chowienczyk P. Dissociation of aortic pulse wave velocity with risk factors for cardiovascular disease other than hypertension: a systematic review. Hypertension 2009; 54: 1328-1336.

27. Schillaci G, De Socio GV, Pucci G, Mannarino MR, Helou $\mathrm{J}$, Pirro $\mathrm{M}$, et al. Aortic stiffness in untreated adult patients with human immunodeficiency virus infection. Hypertension 2008; 52: 308-313.

28. Bonnet D, Aggoun Y, Szezepanski I, Bellal N, Blanche S. Arterial stiffness and endothelial dysfunction in HIV-infected children. AIDS 2004; 18: 1037-1041.

29. van Vonderen MG, Smulders YM, Stehouwer CD, Danner SA, Gundy CM, Vos F, et al. Carotid intima-media thickness and arterial stiffness in HIV-infected patients: the role of HIV, antiretroviral therapy, and lipodystrophy. J Acquir Immune Defic Syndr 2009; 50: 153-161.

30. Lekakis J, Ikonomidis I, Palios J, Tsiodras S, Karatzis E, Poulakou G, et al. Association of highly active antiretroviral therapy with increased arterial stiffness in patients infected with human immunodeficiency virus. Am J Hypertens 2009; 22: 828-834. 
31. Sevastianova K, Sutinen J, Westerbacka J, Ristola M, YkiJarvinen $\mathrm{H}$. Arterial stiffness in HIV-infected patients receiving highly active antiretroviral therapy. Antivir Ther 2005; 10: 925-935

32. Schillaci G, De Socio GV, Pirro M, Savarese G, Mannarino MR, Baldelli $F$, et al. Impact of treatment with protease inhibitors on aortic stiffness in adult patients with human immunodeficiency virus infection. Arterioscler Thromb Vasc Biol 2005; 25: 2381-2385.

33. van Vonderen MG, Hassink EA, van Agtmael MA, Stehouwer CD, Danner SA, Reiss $P$, et al. Increase in carotid artery intima-media thickness and arterial stiffness but improvement in several markers of endothelial function after initiation of antiretroviral therapy. J Infect Dis 2009; 199: 1186-1194.

34. Henry RM, Kostense PJ, Spijkerman AM, Dekker JM, Nijpels $\mathrm{G}$, Heine RJ, et al. Arterial stiffness increases with deteriorating glucose tolerance status: the Hoorn Study. Circulation 2003; 107: 2089-2095.

35. Lazar JM, Wu X, Shi Q, Kagame A, Cohen M, Binagwaho A, et al. Arterial wave reflection in HIV-infected and HIVuninfected Rwandan women. AIDS Res Hum Retroviruses 2009; 25: 877-882.
36. Diehl LA, Dias JR, Paes AC, Thomazini MC, Garcia LR, Cinagawa E, et al. [Prevalence of HIV-associated lipodystrophy in Brazilian outpatients: relation with metabolic syndrome and cardiovascular risk factors]. Arq Bras Endocrinol Metabol 2008; 52: 658-667.

37. Gelenske T, Farias FA, de Alencar X, de Melo HR, de Albuquerque MF, de Carvalho $\mathrm{EH}$, et al. Risk factors in human immunodeficiency virus/acquired immunodeficiency syndrome patients undergoing antiretroviral therapy in the state of Pernambuco, Brazil: a case-control study. Metab Syndr Relat Disord 2010; 8: 271-277.

38. Wolf K, Tsakiris DA, Weber R, Erb P, Battegay M. Antiretroviral therapy reduces markers of endothelial and coagulation activation in patients infected with human immunodeficiency virus type 1. J Infect Dis 2002; 185: 456-462.

39. Mu H, Chai H, Lin PH, Yao Q, Chen C. Current update on HIV-associated vascular disease and endothelial dysfunction. World J Surg 2007; 31: 632-643.

40. Ho JE, Deeks SG, Hecht FM, Xie Y, Schnell A, Martin JN, et al. Initiation of antiretroviral therapy at higher nadir CD4+ T-cell counts is associated with reduced arterial stiffness in HIV-infected individuals. AIDS 2010; 24: 1897-1905. 